Acta Crystallographica Section A

Foundations of Crystallography

ISSN 0108-7673

Received 24 May 2012

Accepted 2 August 2012

\section{Lawrence Bragg's interest in the deformation of metals and 1950-1953 in the Cavendish - a worm's-eye view}

\author{
Anthony Kelly \\ Churchill College, University of Cambridge, Storeys Way, Cambridge CB3 ODS, United Kingdom. \\ Correspondence e-mail: ak209@cam.ac.uk
}

\begin{abstract}
This paper recounts the atmosphere in the Cavendish Laboratory during Lawrence Bragg's triumphant final years there through the eyes and the work of a young research student, and hence reflects some measure of Bragg's personality. The opportunity is taken to deal in detail with Bragg's contribution to our understanding of crystal plasticity, which is seldom described, being overshadowed by his many superb contributions to the determination of crystal structure. Bragg produced in 1940-1942, through his development of the bubble model of a crystal structure, the first demonstration of how crystal dislocations move. His suggestion of the use of microbeams led rather directly to the development of modern thin-film transmission electron microscopy.
\end{abstract}

\section{Introduction}

William Lawrence Bragg (WLB) came to Cambridge from the National Physical Laboratory (NPL) in October 1938, succeeding Rutherford, the New Zealander, as he had done at Manchester. He had been at the NPL only from November 1937. Rutherford was regarded rightly as the father of nuclear physics and was by all accounts a very strong personality; he had died suddenly and Bragg had little time to establish himself at Cambridge before the outbreak of World War II. He was joined in Cambridge in 1939 by E. Orowan, having invited Orowan to come. Orowan was, with G. I. Taylor, the inventor of the concept of a dislocation. Bragg interested Orowan in $\mathrm{X}$-rays and in turn Orowan interested Bragg in the science of the plastic deformation of metals.

When I arrived at the Cavendish to work on metals, Bragg's personal interest had firmly turned away from plastic deformation towards what turned out to be the subject of molecular biology, and so I only saw a small part of his genius. Perutz had first interested WLB in proteins in 1938. It was after World War II, in 1948, that WLB obtained his first grant from the Medical Research Council and published his first paper on the subject in 1950 (Bragg et al., 1950) - the year I started work at the laboratory. Although I was admitted to the laboratory by Bragg (I remember reading the letter with great pride) to work on metals, he was not my supervisor for my $\mathrm{PhD}$. This was W. H. Taylor, who supervised the very small group under Bragg working on Bragg's ideas on metal deformation. We were stimulated and encouraged by Bragg, but the administrative chores of a supervisor were left to Taylor, who looked after us with great care and dedication, and, like Bragg, he never put his name on a paper unless he had himself made a major contribution to it. This arrangement between Bragg and
Taylor was common at the time. I was assigned to this group, I believe, because when interviewed by Schonberg earlier in 1950 I had suggested that I was interested in sub-grains in metals and their analogues as Bitter patterns - in those days, prospective research students were expected to suggest a problem on which he or she would like to work (Kelly, 2005). Although Bragg was losing interest in metal physics and turning his attention almost solely to protein crystallography, nonetheless I was privileged to see first-hand some of his genius. The excellent definitive account of Bragg's life and work contained in David Phillip's Biographical Memoir (Phillips, 1979) is only able to deal briefly with Bragg's interest in metal plasticity during 1940-1942, so I am glad to be able to treat it in a little more detail and what I have to say amplifies the account given there.

When I arrived at the Cavendish Laboratory from the University of Reading, having graduated in physics with firstclass honours, the main research groupings were: nuclear physics, radio astronomy and low-temperature physics, crystallography, and metal physics, associated with Cosslett's group on electron microscopy. Work on metal plasticity consisted of a very small group embedded in crystallography, to which I was assigned. This group had been created by Bragg and was administered by Taylor, together with a much more numerous group named 'metal physics' which was disbanding, having been led by Orowan and which had been working on his ideas. By far the largest group was nuclear physics under Otto Frisch and Edmund Shire.

For completeness I list now the main research groupings when I left the Cavendish, as described by Bragg in his final report - we both left in 1953.

Firstly, crystallography. During this period, dramatic advances in work on the molecular structure of biological 
systems took place with Crick and Watson's elucidation of the structure of DNA and Perutz and Kendrew's solutions of the crystal structures of horse haemoglobin and myoglobin, respectively. The other groups were nuclear physics, radio waves, low-temperature physics, crystallography and electron microscopy, meteorological physics and fluid dynamics. There were also a number of theoretical physicists. Lawrence Bragg was, by all accounts, very supportive of the groups in the laboratory other than his own special interest (crystallography), but there was a general difficulty in the UK at that time with respect to the funding of nuclear research.

\section{Bragg and plastically deformed metals}

Lawrence Bragg and his associates described many of the atomic structures of metals and alloys and, of course, phenomena within these such as order-disorder transformations and the like. A single reference here is not adequate to cover these activities but Bragg (1935) gives a good overview. $\mathrm{He}$ maintained a firm interest in the physics of X-rays throughout his working life. The field in which I knew him was in the study of lattice imperfections in metals and the use of $\mathrm{X}$-ray methods in studying these.

His first paper connected with the distortion of metals was written with his long-time associate Lipson during his short period at the NPL (Bragg \& Lipson, 1938) and is entitled 'Structure of Metals'. This paper was concerned with whether or not the radial displacement of spots on Debye-Scherrer photographs indicated a difference in lattice parameter; this had been suggested by a Dr Muller. Bragg and Lipson showed that the displacement was due to the range of angles over which a crystal reflects radiation - they did this by oscillating the specimen. They remark that the smearing of the spots might give information on the form or the texture of the crystal. They are very polite to Dr Muller and say that experiments on this issue should be continued. The question was still an important one in the early 1950s; Peter Gay and I settled the question as reported in my thesis. We did this again by oscillating the specimen but very precisely using a microbeam (Gay \& Kelly, 1953a). Shortly after the paper with Lipson was written, Bragg gave the opening address to an important meeting at the Royal Society entitled 'A Discussion on the Plastic Flow of Metals' (Bragg, 1938) - Orowan, Taylor, Andrade, Mott, Desch and Preston, the luminaries of the emerging field of metal physics, were there. WLB gave an outline of the problems of crystal flow and slip which needed to be understood with a soundly based theory.

Shortly after the outbreak of war, in January 1940, WLB made his own contribution concerning plastic deformation entitled 'The Structure of a Cold Worked Metal' (Bragg, 1940). This paper was part of a symposium organized by the Physical Society on Internal Strains in Solids and consisted of four parts: Slip in Single Crystals, to which Orowan contributed, of course; Precipitation in Metals and Age Hardening; the Effects of Cold Work; and Other Effects of Internal Strains. Here Bragg would have been exposed again to a whole range of problems in physical metallurgy. His paper introduced the idea of a foam structure of a cold-worked metal, to which he had briefly alluded in 1938, in which he considered the stability of the cold-worked state and compared the structure of the foam with the domain structure of $\mathrm{Cu}_{3} \mathrm{Au}$ order-disorder alloys.

In the years before and just after the war, understanding how dislocations enable plasticity and the properties of the dislocations were essential problems, and even the existence of these well defined defects was questioned.

During 1940, having attended the Physical Society Conference in January, the question of the plastic flow of metals must have been one of his main interests (apart from his work in supporting the war effort), if not his principal research interest, since later that year he developed his bubble model of the crystalline structure of a metal, carrying out the first experiments with his son Stephen during the latter's summer holidays in 1940 and early 1942. The summer of 1941 was spent by Bragg in Canada - he was there from March until September of that year as a scientific liaison officer. By the early spring of 1942 he had developed and expounded the first account of his theory of the flow stress (Bragg, 1942a) and by the summer had submitted for publication the first experiments on the bubble model (Bragg, 1942b) (see $\$ 4$ below). The background to his thinking in those years is contained in an address to the North East Coast Institution of Engineers and Shipbuilders (Bragg, 1944), where he delights in describing the bubble raft.

The joint discoverers of dislocations were Orowan (1934), Polanyi (1934) and Taylor (1934), who did so independently of one another. Orowan came to Britain from Germany in 1937 and worked at Birmingham with Peierls. In 1939 he joined Bragg at the latter's invitation, and spent the war years in Cambridge. According to Bragg 'he was volatile and irrepressible and had a most fertile imagination and mind'. After the war he attracted a large number of later well known scientists to study metal physics. These included J. F. Nye, N. J. Petch, R. W. K. Honeycombe, P. L. Pratt, E. O. Hall, R. W. Cahn and G. W. Greenwood, as well as W. M. Lomer. Both Nye and Lomer were 'lent' to Bragg for a year to work on the bubble model - see below. John Glen was also in this section when I arrived, working with Perutz and following up the latter's interest in the flow of ice derived from the famous Habbakuk project of 1942/43. From some of these I garnered much good advice in my first year, before they gradually disappeared over the years 1950-1952: a fine description of the work of Orowan's group is given by J. F. Nye in Orowan's obituary (Nabarro \& Argon, 1995). This group flourished at the Cavendish until Orowan left in 1950 for MIT because he could not get a satisfactory permanent position at Cambridge. In fact he entered the Secretary's (E. H. K. Dibden) office to bid farewell as I was being inducted into the lab by Dibden! Notably, between 1939 and 1950 two of the principal discoverers of dislocations were working in Cambridge and, of course, Bragg knew both well. As he did Polanyi in Manchester.

The suggestion that the atomic displacements necessary to account for plasticity were facilitated by the motion of dislo- 


\section{Bragg centennial}

cations which affected atoms of spacing just a few ångstroms apart needed to be related to the observation of slip lines with the optical microscope which are spaced, at least, a micron, i.e. thousands of atoms, apart. Ewing \& Rosenhain (1899, 1900) had shown that when plastic flow occurs in metals, slip lines appear on the surface that are quite similar to those observed in rock salt - a brittle substance - by Reusch (1867).

In the 1930s and '40s X-rays were almost the only means of studying the internal structure of a metal specimen so as to elucidate the nature of plasticity. The penetration depth of $\mathrm{X}$-rays into the common metals under normal conditions is small, e.g. for $\mathrm{Cu} K \alpha$ radiation only a few tens of microns. Examination of cold-worked metals by back-reflection techniques or by the Debye-Scherrer method was found to show that the lines were excessively broadened in a radial direction. In addition, if the grain size was large enough the spots from an undeformed polycrystal would be found to expand along the arc of a Debye-Scherrer photograph after small deformations. At larger deformations the rings were continuous, and they became increasingly broad with further deformation until the broadening appeared to saturate. An example is shown in Fig. 1. Laue photographs of single crystals taken with white X-radiation from an undeformed metal crystal showed sharp spots, but when lightly deformed these spots became elongated into streaks; the phenomenon called asterism. This streaking was taken to indicate that the perfect crystal was showing a range of orientation - a sort of induced mosaic structure. X-rays were at the time the only means of looking inside a metal and even then there was no X-ray microscope,

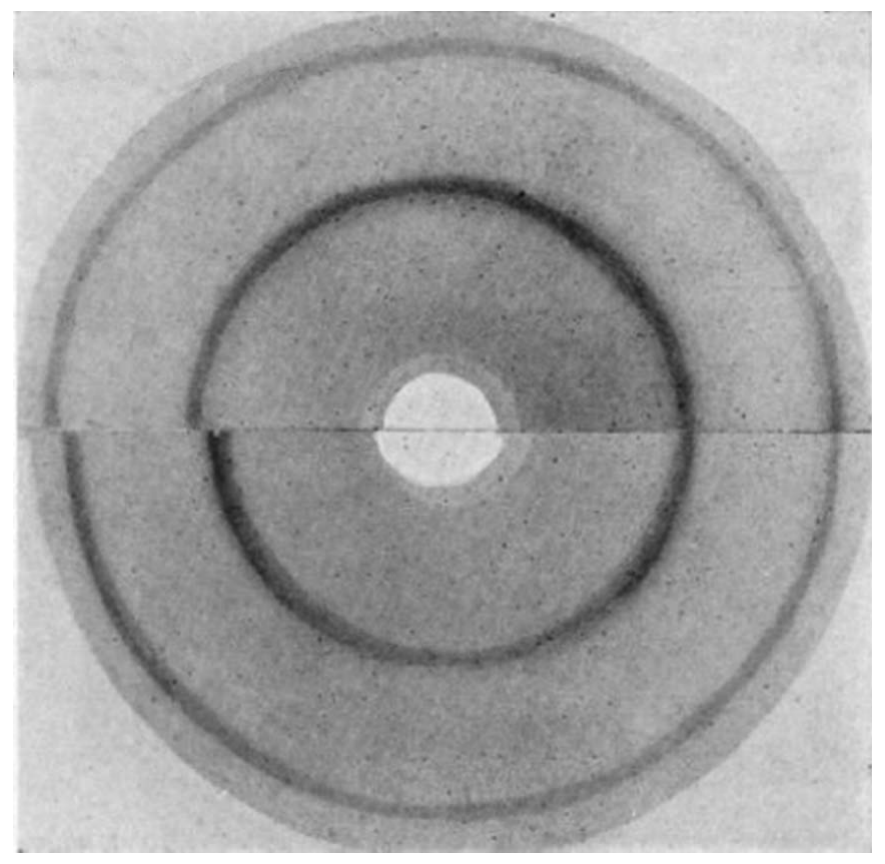

Figure 1

Back-reflection photograph of silver deformed $65 \%$ (upper) and $70 \%$ (lower) showing broadening of the Debye-Scherrer (331) and (420) rings: from Wood (1939). Wood found that recovery occurs in this metal after $65 \%$ deformation. Reproduced with permission from Proceedings of the Royal Society A. so that information could only be gained from study of the diffraction maxima.

There were two accepted possibilities for the cause of the line broadening. These were that it was due to a range of elastic strains being present in the worked metal, or that the broadening was caused by the fact that deformation had fragmented the lattice into very small crystals and these were giving broadened diffraction peaks due to the shape transform of the crystal. These were designated the theory of mean strains or of particle-size broadening.

The stress necessary to initiate slip in a virgin metal crystal is so small as to be hardly measurable with any accuracy, as Bragg noted (Bragg, 1942a), but the yield stress of a coldworked metal can be stated. Otherwise, to quote WLB 'the engineer would have no basis for his calculations'. This first paper (Bragg, 1942a) sets out his approach and in it he thanks Orowan for helpful discussion and criticism and refers to Orowan (1942) on the spacing of slip lines as having given him (WLB) his fundamental idea. This was to estimate the yield stress of a cold-worked metal from his own picture of the coldworked state. This state was consistent with the X-ray observations of Gough and Wood - namely a mosaic of variously oriented crystallites within a single-crystal grain. These crystallites or mosaic fragments consisted of relatively perfect regions separated by heavily distorted ones. He accepted Wood's estimate (Wood, 1939) of their size. Bragg's chosen criterion for further deformation was that it should lead to a reduction in strain energy. He preferred this approach to that of G. I. Taylor (Taylor, 1934) because 'it makes no postulate about the arrangements of dislocations but is based on the average fragment size for which there is direct x-ray evidence'. He also refers to his description of the cold-worked state in Bragg (1940). In the first paper, the form of the governing equation is given and in the two later papers (Bragg, 1948, $1949 b$ ) he gives a more detailed treatment - see the formula in the discussion of my PhD thesis in $\$ 3$ of this paper. In his 1948 paper, Bragg sets down the form of his formula for the yield stress of a cold-worked metal and the penultimate sentences explain the genesis of the microbeam, as follows:

The above is a tentative and very general discussion of this very interesting problem. It suggests however, that the relation

$$
\gamma_{\lim }=\text { const.s/t }
$$

may be found to hold with a very similar value of the constant of order unity for a number of typical metals $\left[\gamma_{\lim }\right.$ is the limiting shear strain and s the inter-atomic distance]. This cannot be tested because we have so little information about the values of $t$ which measures the extent in any direction of a cold worked metal to which the regularity of the atomic arrangement continues unchanged. More experimental results are much to be desired, obtained by $x$-ray analysis, the electron microscope, or other means.

He suggested a possible means of finding $t$ and of resolving the controversy over the origin of line broadening, in a characteristically direct way. It was known, of course, that if a specimen contained only a small number of crystals of iden- 
tical structure, then the Debye-Scherrer rings would be spotty. By counting the number of spots on a particular $(h k l)$ ring one could, if one knew the volume irradiated, deduce the average volume of the individual particles being irradiated. With conventional X-ray beams continuous rings were produced, so WLB argued that if one irradiated the metal with a sufficiently fine beam or microbeam of very small diameter, then a continuous ring should be resolved into spots. A very fine physical judgement.

\section{The X-ray microbeam}

To do what was required successfully, $\mathrm{X}$-rays must be produced in a very fine beam and hence to proceed, with manageably short exposure times, a very powerful X-ray source was needed. Bragg gave the initial development to J. N. Kellar in July 1946 (Kellar, like me, had come from Reading). He was joined by P. B. Hirsch in October of that year, with Kellar concentrating on developing a rotating-anode X-ray tube and Hirsch on collimating a fine beam. J. S. Thorp joined the team in October 1947 and P. Gay in the same month in 1948. After Kellar's death in July 1948, Hirsch, Thorp and Gay completed the project so that the X-ray tube and the camera for taking X-ray photographs with a very fine beam were completed and functioning (Gay et al., 1951) when I joined the team in October 1950. During my first year Gay was concerned with writing his $\mathrm{PhD}$ thesis - submitted in August 1951. During my last year I was joined by W. T. Roberts, a post-doc.

By the time I arrived, Bragg's 'fine physical judgement' had been confirmed by experiments on aluminium. Kellar et al. (1950) showed that with a beam of $35 \mu \mathrm{m}$ diameter, the continuous ring obtained with X-ray beams of normal diameter was resolved into spots - the average particle size was determined to be about $2 \mu \mathrm{m}$, and from the broadening of the individual spots the particles were shown to be distorted.

Hirsch wrote his thesis in 1950 and left the team to work on coal - very fashionable at that time - supported by the National Coal Board, and Gay introduced me to the microbeam techniques in that year. It was my job to provide examples of the use of this fine microbeam. I was able to show unequivocally that the so-called Neumann bands occurring in deformed crystals of iron were in fact twins, as had been expected (Kelly, 1953a), and to settle the question referred to above of the variability of lattice parameter (Gay \& Kelly, 1954).

Gay and I extended the microbeam examination to other metals. A series of papers describing the results on polycrystalline metals deformed by rolling resulted (Gay \& Kelly, $1953 a, b)$. These repeated the type of examination carried out on aluminium. The softer metals, $\mathrm{Sn}, \mathrm{Zn}, \mathrm{Pb}$ and $\mathrm{Cd}$, showed recrystallizaton after heavy rolling. With the harder metals, $\mathrm{Cu}, \mathrm{Ni}, \mathrm{Fe}$ and $\mathrm{Au}$, it was not possible to resolve the DebyeScherrer rings using the microbeam back-reflection technique. The results for all the metals that we studied were reported in a third paper (Gay et al., 1954), which introduced a picture of the cold-worked state (see below).
In addition, I used electron microscopy (only a surface replica method was available) in conjunction with X-rays to set limits to the grain size in electrodeposited chromium.

My work followed closely that of P. B. Hirsch, who was a great help, and in my first year very much my mentor naturally, he wanted to see his 'creation' very properly used. I realised that some limitations of the microbeam technique when used to take back-reflection photographs might be overcome by making specimens thin enough so that transmission photographs could be taken and spotty DebyeScherrer rings obtained from particles of linear dimension less than a micron. In this way I obtained resolved spots from deformed copper. The advantages of the use of transmission over back reflection were that the irradiated volume was known and exposure times were much shorter. When using the back-reflection method, a rather involved procedure, employing two films to register the reflections, had been developed by Hirsch. The use of a transmission method led quite naturally to the suggestion of examination by electron diffraction and I set out to try this.

By repeated rolling of a gold foil sandwiched between aluminium slabs, I produced a specimen of gold thin enough to be examined both by $\mathrm{X}$-ray transmission and by electron diffraction (see Fig. 2) and successfully obtained spotty rings from individual crystals (Kelly, 1953b). The size of these was $0.1-0.3 \mu \mathrm{m}$, an order of magnitude smaller than could be obtained using X-rays. The volume of such a crystal is $\sim 10^{-15} \mathrm{~cm}^{3}$ and this greatly interested Sir Lawrence on the occasion when I showed him the photograph. ${ }^{1}$

The diffraction patterns were supplemented by examination in the electron microscope and a single rather blurred transmission photograph was obtained, which is published in my thesis (Kelly, 1953b). This, at the time was a minor breakthrough because most electron-microscope photographs were taken of replicas of the surface due to the electrons not being able to penetrate the specimen, although transmission electron micrographs had been obtained previously by Heidenreich (1949). The examination of gold foils by electron diffraction was carried further (Hirsch et al., 1955).

Three years after I left to go to the University of Illinois, Hirsch, with Whelan, who had pursued the use of transmission electron micrographs with microscopes of much higher resolution, first observed (simultaneously with Bollmann) and correctly interpreted images of moving dislocations. Hirsch (1980) recalls the events vividly, but his account is in slight error regarding my own movements. The motion and interaction of individual dislocations could then be studied in detail and there was little further for X-rays to do in this regard. But it may be said that this triumph flowed quite directly from Bragg's intuition in suggesting the development of the microbeam. Howie (2002) delineates some of the subsequent developments.

\footnotetext{
${ }^{1}$ Had I read Heidenreich (1949) - published two years earlier - I would probably not have attempted to thin my gold by so crude a method. This illustrates Bragg's often quoted dictum to young researchers not to read the literature too much - though I never heard him say that myself.
} 


\section{Bragg centennial}

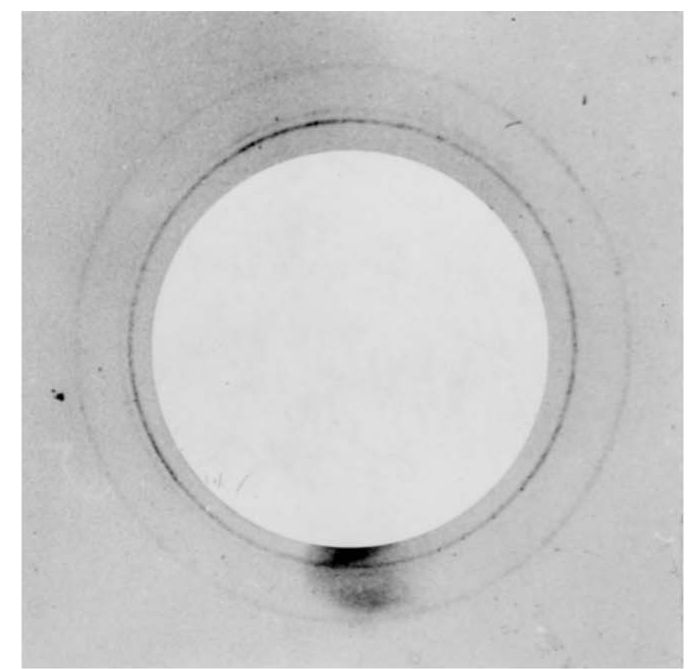

(a)

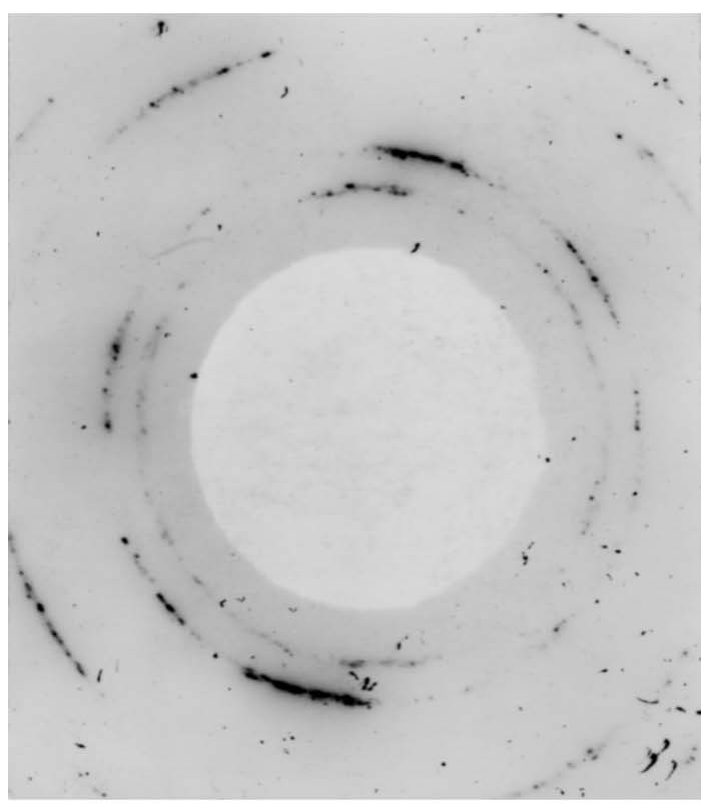

(b)

\section{Figure 2}

Transmission diffraction patterns of heavily deformed gold. (a) Using X-rays: (111) reflection; beam diameter $8 \mu \mathrm{m} ; \lambda=1.54 \AA$. (b) With electrons: (111), (200) and several more rings; beam diameter $10 \mu \mathrm{m} ; \lambda=$ $0.043 \AA$.

As a result of the microbeam work, a number of papers were published on the nature of the cold-worked state. We were able to make the first direct measurement of dislocation density in a cold-worked metal (Gay et al., 1953) and to make other observations on the clustering of dislocations into illdefined boundaries so as to produce an array of heavily distorted regions containing many dislocations separated by relatively dislocation free areas, designated by us as 'crystallites' (Gay et al., 1954) and later clearly identified by electron microscopy.

Bragg's interest in the cold-worked state of metallic matter had resulted in his theory of this, culminating in the work described in Bragg (1949b). This estimated the yield stress of a heavily-cold worked metal, the ultimate tensile strength
Table 1

Comparison of calculated and experimental values of the strength of metals.

\begin{tabular}{lllll}
\hline & $\begin{array}{l}\text { Limiting } \\
\text { particle } \\
\text { size }(\mu \mathrm{m})\end{array}$ & $\begin{array}{l}\text { Strength using } \\
\text { Bragg criterion } \\
\left(10^{8} \text { dynes cm }^{-2}\right)\end{array}$ & $\begin{array}{l}G / 3(b / t)^{1 / 2} \\
\left(10^{8} \text { dynes cm }^{-2}\right)\end{array}$ & $\begin{array}{l}\text { Experimental } \\
\text { ultimate } \\
\text { strength } \\
\left(10^{8} \text { dynes cm }{ }^{-2}\right)\end{array}$ \\
\hline $\mathrm{Al}$ & 2.5 & 1.5 & 7.9 & 7.5 \\
$\mathrm{Fe}$ & 1.5 & 7.4 & 33 & 34 \\
$\mathrm{Cu}$ & 0.6 & 9.7 & 28.8 & 23 \\
$\mathrm{Zn}$ & 8 & 0.78 & 6.3 & $12-30$ \\
$\mathrm{~Pb}$ & 6 & 0.21 & 1.4 & 2.1 \\
\hline
\end{tabular}

(UTS), in terms of its structure and elastic constants. The idea was that yield would only occur if further slip within the distorted structure led to a local reduction in strain energy. He assumed that the structure of a cold-worked metal was that of a type of foam, and postulated that the size of the units of the foam determined the elastic limit for further deformation. The final chapter of my thesis was principally devoted to a test of this based upon my results from the microbeam examination.

Bragg's criterion was that the UTS $\sigma$ should be given by the expression

$$
\sigma \geq G b / t[1.46 \log (t / b)+0.6]
$$

where $G$ is the shear modulus, $b$ is the interatomic distance and $t$ is the observed particle size. He used figures for the particle size deduced from X-ray line broadening to establish his idea. I used my own figures deduced from the X-ray microbeam results. Table 1, taken from my thesis, shows the result and includes a figure derived by us based on the idea of dislocation pile-ups controlling the flow of a heavily worked metal (Gay et al., 1954). Bragg's criterion as an inequality is obeyed.

By the time I wrote my thesis in the summer of 1953, Bragg was little to be seen in the lab, since he was preparing to go to the Royal Institution. I never discussed this result with him.

Our theory at the time appeared to be in rough accord numerically with the rather messily defined experimental number representing the UTS. However, modern observation and theories do not differ in the essentials. The heavily coldworked state is still described in terms of a cell structure in which there are relatively dislocation free regions separated by regions of very high dislocation density, as in Fig. 3 (for example Argon, 2008). Bragg's picture of a cell structure is essentially correct, although the detailed quantitative relationship of cell size to yield stress is much more sophisticated.

\section{The bubble model of a crystal structure}

The invention of the bubble model of a metallic structure is a striking example of Bragg's genius. The bubble model demonstrated very clearly the nature of dislocation motion when this was still regarded as an unproven theoretical possibility. It was the bubble model which gave a picture of how dislocations behave and was the main experimental evidence for their existence. 


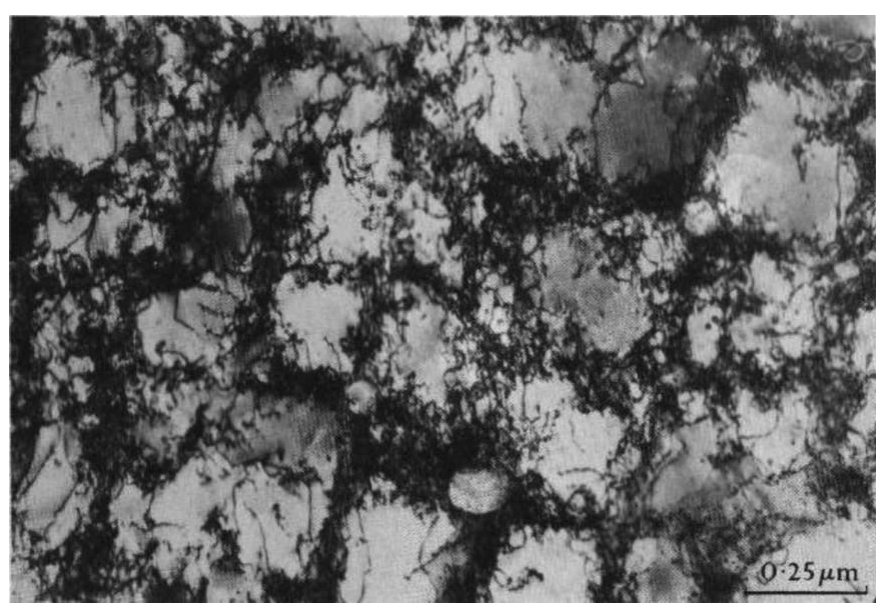

Figure 3

Transmission electron micrograph of heavily deformed copper (Kelly \& Macmillan, 1986).

As we have seen, WLB conceived the idea during the war as he was developing his ideas on the geometry of the distortions of crystals in the cold-worked state and his theory of the yield point of a cold-worked metal, i.e. in 1940-1942, before the publication of the definitive paper on his theory of the yield point (Bragg, 1949b). According to his unpublished autobiography (private communication from S. L. Bragg) and the memories of his children, he first thought of using lentils floating on water and then of bubbles, and asked Lipson to help him, but Lipson's bubbles were too large. Bragg had noticed while mixing the fuel for his motor mower that equalsized small bubbles were produced which clung together on the surface to form a regular pattern, as in a crystal. The early experiments were carried out by him with George Crowe, who had been Rutherford's great assistant (and always wore a bow tie when I knew him, which was quite rare in those days). They were given some assistance by Stephen Bragg, Lawrence's eldest son, on his holidays from Rugby school, in carrying out the first experiments during the latter's summer holidays in 1940 and also early 1942. Orowan is reported to have solved the problem of getting the bubbles to be of uniform size.

The first paper (Bragg, 1942b) on the bubble model describes all of the essentials, including a stress-strain curve. The full power of the bubble model was developed and published in papers with Nye (Bragg \& Nye, 1947) and with Lomer (Bragg \& Lomer, 1949) after the war. The paper with Nye describes the structures that may be obtained and that with Lomer the amazing quantitative experiments. The genesis and power of the technique has been beautifully and succinctly described by Mick Lomer (Lomer, 1990), who showed it to me and also gave me very good advice when I was writing my thesis. Mick Lomer was one of the few of us who was officially supervised by WLB.

Bragg's infectious enthusiasm for the demonstration of dislocations is very well recorded by Lomer and it may be seen in WLB's own words in his article in Physica (Bragg, 1949a), based on a lecture he gave in April of that year to the Physics Society of the Netherlands. Lomer also points out that it was

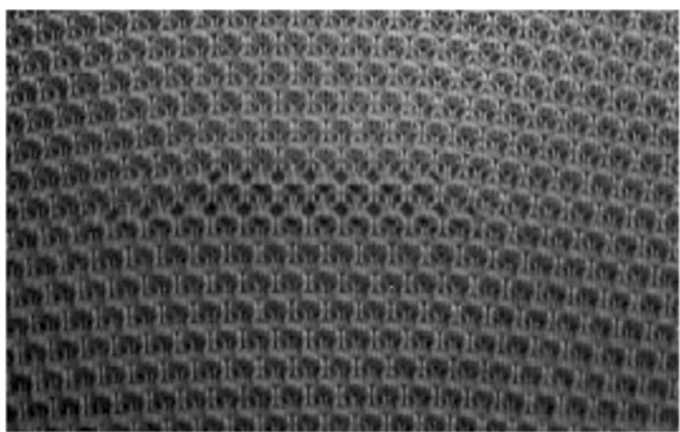

Figure 4

A partial dislocation in a three-dimensional raft subject to a bending strain. Bubble diameter 0.7 mm. (Part of Fig. 18 of Bragg \& Nye, 1947). Reproduced with permission from Proceedings of the Royal Society A.

Bragg who produced for the first time the excellent analogy for dislocation motion afforded by considering moving a heavy carpet by first forming a ruck and then moving the ruck with one's feet. And Nye (personal communication) speaks of how

Bragg had three separate layers of ping-pong balls glued together in close packing. He used these to demonstrate hcp and fcc packing, and also to illustrate slip. He pointed out that for one layer to slip one unit over another layer it would prefer to do it in two half steps, and he speculated on what might happen if a different slip plane at an angle tried to break through. He wrote and sent off a paper on it to Nature, and it fell to me to tell him that Shockley had already published the idea of partial dislocations at the Pittsburgh Conference.

In 1952 Nye himself found that a partial dislocation is in fact visible in one of the photographs of the three-dimensional bubble rafts. This is reproduced in Fig. 4, which John Nye kindly sent to me.

Distinct from previous models of atoms in crystals in which the number of atoms is limited in number, here 100000 bubbles were easily made of controlled diameter between 0.1 and $2 \mathrm{~mm}$ diameter - the smaller the more rigid. Bragg \& Nye (1947) observed structures which had been supposed to occur in metals.

These two dimensional crystals show structures which have been supposed to exist in metals and simulate effects which have been observed such as grain boundaries, dislocations and other types of fault, recrystallization, annealing and strains due to foreign atoms.

In his article in Physica, WLB discusses recrystallization and, with proper caution, draws the attention of the reader to the lack of thermal effects in this model.

By stirring up a two-dimensional array with a rod one can momentarily break it into a mass of extremely small crystals full of dislocations and faults. If this mass is left to itself, recrystallization is at first very rapid. Within a second, the surface is covered with a mosaic of small crystallites which have rather irregular boundaries. Recrystallization then becomes slower, but goes on for half an hour or more. The larger crystals 'eat up' the small ones, boundaries straighten out, faults 


\section{Bragg centennial}

disappear, until the surface is covered by a few large and very perfect crystals. It is not justifiable to compare this recrystallization too closely with that of a metal, because there is no effect analogous to thermal movement. The tempo is set not by the thermal movements overcoming energy barriers, but by the viscosity of the solution.

Three-dimensional (although thin) specimens could be made and plastically deformed. Poisson's ratio of the rafts was measured. It was even possible to measure the yield stress of such a raft and to show that the ordinary metals must contain dislocation-like defects, otherwise their measured strength would be much larger than is found in practice.

The paper describing the bubble model is reproduced in full by Richard Feynman in his Lectures on Physics (Feynman et al., 1964). A tribute from one of the finest teachers of physics to another one.

\section{A research student's view of the Cavendish}

Many fresh graduates who came to Cambridge as research students having recently graduated from another university, as did I, were conscious of the need to assure ourselves that our training in physics at another place had been adequate. I came from Reading, where J. A. Crowther had been Professor and was followed by R. W. Ditchburn, both of whom had been at the Cavendish during Rutherford's time, but both had worked with J. J. Thomson. We attended Part II lectures and sometimes those in mathematics. I went to hear Dirac and that convinced me that I am no theoretician. One was also tried in a number of ways - one was foreign to the Cambridge supervision system - a magnificent but very expensive way of teaching. The opportunity to supervise really taught me physics. To be accepted, as I was, but only in my third year, as being capable of supervising undergraduates in physics for Trinity was felt by me to be a palpable achievement - other colleges allowed me to do this in my second year. To be invited to attend a meeting of the Kapitza Club I regarded as a great accolade - I was asked to do so in my third year, and among other sessions remember one by F. C. Frank, who had just solved the mystery of crystal growth from saturated solutions by the introduction of dislocations.

At the time when I entered the Cavendish one was expected to be very familiar with common laboratory practical skills such as glass blowing, simple use of the lathe and elementary electronics. If a piece of apparatus such as an amplifier did not work, one was forced to repair it oneself. A course on techniques was taught to first-year postgraduate students by A. S. Baxter, a knowledgeable New Zealander of great practical skill. In addition, if one entered the crystallography section one was sent to the Department of Mineralogy to learn classical crystallography and point groups and space groups, all done with copious diagrams - no mention of group theory. These activities brought the new students into the cohort of Cambridge graduates.

The shadow of the Cavendish's successes in nuclear physics in the 1930s still clung to the lab, and seeing Lise Meitner chatting to her nephew Otto Frisch at the tea table and a visit from Hans Bethe reminded one of the nearness then to the discovery of nuclear fission. Although the groups were friendly, one frequently got to know the members of the sections housed in the same building much better than one did members of the other groups. We in the crystallography section were in the Austin Wing and hence I knew as a fellow student Francis Crick (though he was somewhat older than me) and Watson as a young and very ambitious post-doc. Crick was very kind to me and gave me some good advice, besides having a very good knowledge of the kinematic theory of diffraction - after he became very famous, people did not realise that his early training had been in physics, and I have always thought that it was his knowledge of physics which gave him a lot of his intellectual self-confidence. And, of course, Kendrew and Perutz - the latter only mildly objected to Mike Bown and me playing cricket using rubber bungs as balls in the third-floor corridor. (There were only three floors at that time.) Eric Howells, who with Bragg solved the crystal structures of imidazole and methaemoglobin and helped Perutz with haemoglobin, was a close friend. I vividly remember on occasion Crick shouting down the corridor on the first floor and Watson's disdain for others little younger than him. Crick would sometimes jump to his feet in the middle of a colloquium and debate with the speaker. Eric said to me in 1951 'Francis is insufferable - only a Nobel Prize will justify it'. And I recall the wonderful party given by W. E. (Bill) Cochran in his rooms in Trinity Hall on 23 March 1953. Crick was in tremendous form and we realised soon afterwards why. The famous paper with Watson on the solution of the structure of DNA was just about to be sent to Nature (Watson \& Crick, 1953). Odette, Crick's wife, recalled with me that party many years later. Very many famous names in the development of $\mathrm{X}$-ray crystallography came as visitors, such as: W. Zachariasen; Isidor Fankuchen; R. W. James (the author of that wonderful text 'The Optical Principles of the Diffraction of X-rays', who had been in the Antarctic with the Shackleton expedition and was a long-time associate of Bragg before going to Cape Town) and, of course, Rosalind Franklin who came to see Crick and also incidentally Peter Hirsch - she had also worked on coal; Kasper; B. E. Warren from MIT; Pepinsky and others. Some of those mentioned appear in Fig. 5.

Bragg was a kindly supervisor and I saw him perhaps three times in my first and second years - in my first few weeks he opened a seminar on metal deformation with emphasis on the importance of simple experiments and clear models of the deformed metallic state. I did not see him in my last year. I always addressed him as Sir. He listened and made penetrating comments which he remembered the next time that we met. He was very familiar with the microbeam and suggested that we exhibit the camera and some results to a Royal Society Conversazione in 1952 where, unfortunately, I undertook to explain the nature of X-ray diffraction to C. G. Darwin! Bragg was delighted when I obtained a spotty ring from copper and he remarked that we were obtaining individual reflections from crystals of volume less than $10^{-12} \mathrm{~cm}^{3}$, and became more 


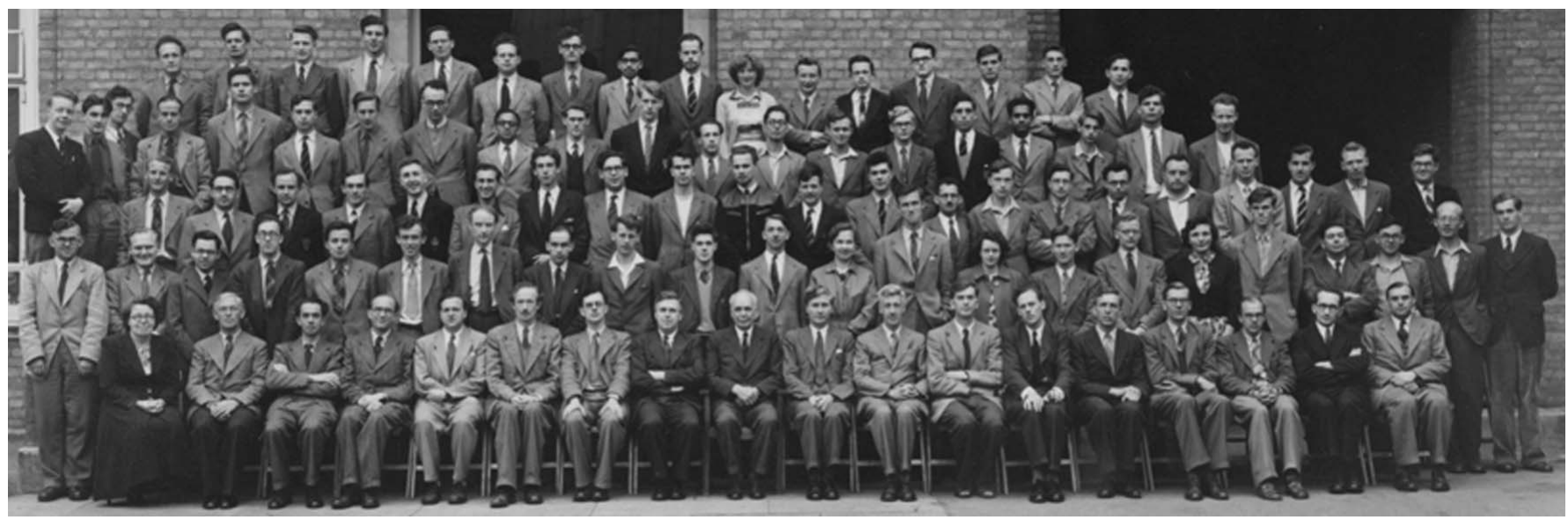

\section{Figure 5}

Cavendish Laboratory physics research students, June 1952. WLB is the central seated figure with Taylor on his left and Schoenberg on his right. Cosslett, Cochran and Ashmead are second, third and fourth from the left seated, with Dibden at the extreme right seated with Baxter next to him. Watson and Crick are sixth and seventh from left in the first row standing with Kendrew seventh from the right. I am on the extreme left of the second row standing with Howells third from left. Bown is second from left in the back row with Hirsch sixth from left.

excited with the results of the examination by electron diffraction. I thought that his interest stemmed from his interest in his own theory of the yield point of a metal, which he had related to sub-grain size (Bragg, 1949a), but subsequently appreciated that he was more probably thinking of obtaining diffraction patterns from small and weakly scattering crystals of biological structures. I say this because Phillips (1979) states that he asked for our rotating-anode high-intensity X-ray source to be diverted to the study of proteins and, at the time, D. H. G. Broad was designing a rotating-anode tube for the protein group.

Of course I went to some of his Part II lectures in physics they were superbly clear and I recall in particular his remarks on the flow of a granular material complete with a wonderful demonstration and the explanation, so vividly given, of how footprints on a wet sandy beach behave.

Bragg always entertained his PhD students early in their course at his home in West Road. On one occasion my nose started to bleed and Lady Bragg was kindness itself and so discrete that others did not notice.

I remember when I spoke to him on one occasion without adequate preparation and so explained myself rather badly. Bragg told me to go away and to get my ideas clear, which I duly did. He often dealt through Taylor and sometimes after a visit by WLB to my room W. H. Taylor would come in and announce whether I had done well or badly.

I last met him at a meeting of the Royal Society Dining Club in January 1970 - I was not then a member - and I recall well, after someone had raised a question (I think about field theory) that he with great intensity insisted that there was plenty of mysterious physics to be found in understanding the gyroscope.

\section{Conclusion}

Bragg was a magnificent physicist and showed this in all that he did. But when I joined the laboratory five years after the war in 1950 and so 13 years after Rutherford's death, Rutherford's legacy was still strong and indeed, by many, WLB was not regarded as a real physicist but as a lesser beast - a crystallographer. This opinion would often come out at the Cavendish Christmas parties; it was perhaps engendered by the lack of emphasis on nuclear physics, which some regarded as the Cavendish's own area of expertise. Bragg, in his unpublished autobiography, shows that he agonized about the continuation of a major effort in nuclear physics, but like others of good sense, knew that the palm had passed to the USA because of the massive cost of the machines necessary to work at the cutting edge of research. The idea that he was not a true physicist was extraordinarily silly, because, as Bernal wrote to him (Phillips, 1979) on Bragg being awarded the Copley medal of the Royal Society (its highest honour) in 1966 'Three new subjects, mineralogy, metallurgy and now molecular biology, all first sprang from your head, firmly based on applied optics'.

In the case of metal physics his largest contribution was the bubble model, which removed so many of the doubts concerning the existence of dislocations and indeed actually showed the motion of individual two-dimensional dislocations. The invention of thin-film electron microscopy to observe dislocation motion was perhaps inevitable with the technical advances of electron microscopy, but due to Bragg's prior development of the microbeam the technique became available to persons so well able to understand the physics of contrast and to exploit the advance so quickly and expertly that he must be regarded if not as the father then certainly as the most important grandparent!

I am very grateful to Stephen Bragg for allowing me to read WLB's unpublished autobiography and to Lady Heath (WLB's elder daughter) for a short reminiscence. John Nye has been kindness itself in describing the work on the bubble raft and providing Fig. 4. The following have read and 


\section{Bragg centennial}

commented most helpfully on the typescript: Archie Howie, John Nye, Mick Lomer, Mike Stowell and Sir Peter Hirsch. I am also grateful to Bonnie Cooper for helping me with the illustrations, to Charles Johnson for assistance with the figures, and to Ana Talaban-Bailey for assistance in the typing of the final copy.

\section{References}

Argon, A. S. (2008). Strengthening Methods in Crystal Plasticity, ch. 7. Oxford University Press.

Bragg, W. L. (1935). J. Inst. Met. 56, 275-299.

Bragg, W. L. (1938). Proc. R. Soc. London Ser. A, 168, 302-303.

Bragg, W. L. (1940). Proc. Phys. Soc. 52, 105-109.

Bragg, W. L. (1942a). Nature (London), 149, 511-513.

Bragg, W. L. (1942b). J. Sci. Instrum. 19, 148-150.

Bragg, W. L. (1944). Trans. North-East Coast Inst. Eng. Shipbuild. 60, 299-306.

Bragg, W. L. (1948). Phys. Soc. London, pp. 26-29.

Bragg, W. L. (1949a). Physica, 25, 83-91.

Bragg, W. L. (1949b). Proc. Cambridge Philos. Soc. 45, 125-130.

Bragg, W. L., Kendrew, J. C. \& Perutz, M. F. (1950). Proc. R. Soc. London Ser. A, 203, 321-357.

Bragg, W. L. \& Lipson, H. (1938). Nature (London), 141, 367-368.

Bragg, W. L. \& Lomer, W. H. (1949). Proc. R. Soc. London Ser. A, 196, 182-194.

Bragg, W. L. \& Nye, J. F. (1947). Proc. R. Soc. London Ser. A, 190, 474-481.

Ewing, J. A. \& Rosenhain, W. (1899). Proc. R. Soc. London Ser. A, 65, 85-90.

Ewing, J. A. \& Rosenhain, W. (1900). Philos. Trans. R. Soc. London Ser. A, 193, 353-375.

Feynman, R. P., Leighton, R. B. \& Sands, M. (1964). Lectures on Physics II, pp. 30-10. Reading: Addison-Wesley Inc.
Gay, P., Hirsch, P. B. \& Kelly, A. (1953). Acta Metall. 1, 315-319.

Gay, P., Hirsch, P. B. \& Kelly, A. (1954). Acta Cryst. 7, 41-49.

Gay, P., Hirsch, P. B., Thorp, J. S. \& Kellar, J. N. (1951). Proc. Phys. Soc. London Sect. B, 64, 374-386.

Gay, P. \& Kelly, A. (1953a). Acta Cryst. 6, 165-172.

Gay, P. \& Kelly, A. (1953b). Acta Cryst. 6, 172-177.

Gay, P. \& Kelly, A. (1954). Acta Cryst. 7, 333-336.

Heidenreich, R. D. (1949). J. Appl. Phys. 20, 993-1011.

Hirsch, P. B. (1980). Proc. R. Soc. London Ser. A, 371, 160-164.

Hirsch, P. B., Kelly, A. \& Menter, J. W. (1955). Proc. Phys. Soc. London Sect. B, 68, 1132-1145.

Howie, A. (2002). Understanding Materials, edited by C. J. Humphreys, pp. 37-50. London: Maney/Institute of Materials.

Kellar, J. N., Hirsch, P. B. \& Thorp, J. S. (1950). Nature (London), 165, 554-556.

Kelly, A. (1953a). Proc. Phys. Soc. London Sect. A, 66, 403-405.

Kelly, A. (1953b). PhD thesis, University of Cambridge, England.

Kelly, A. (2005). Compos. Sci. Technol. 65, 2285-2294.

Kelly, A. \& Macmillan, N. H. (1986). Strong Solids, 3rd ed, Plate 4, p. 34. Oxford: Clarendon Press.

Lomer, W. M. (1990). The Legacy of Sir Laurence Bragg, edited by J. M. Thomas and D. Phillips, pp. 115-118. Northwood: Science Reviews Ltd.

Nabarro, F. R. N. \& Argon, A. S. (1995). Egon Orowan in Biographical Memoirs of Fellows of the Royal Society, 41, 315-340.

Orowan, E. (1934). Z. Phys. 89, 634-659.

Orowan, E. (1942). Nature (London), 147, 452-453.

Phillips, D. (1979). Biographical Memoirs of Fellows of the Royal Society, 25, 75-143.

Polanyi, M. (1934). Z. Phys. 89, p. 660.

Reusch, E. (1867). Poggendorf's Ann. Phys. Chem. 132, 441-451.

Taylor, G. I. (1934). Proc. R. Soc. London Ser. A, 145, 372-387.

Watson, J. D. \& Crick, F. H. (1953). Nature (London), 171, 737-738.

Wood, W. A. (1939). Proc. R. Soc. London Ser. A, 172, 231-241. 